\title{
Strategy for the Customized Mass Screening of Genetic Sensorineural Hearing Loss in Koreans
}

\author{
Mun Young Chang ${ }^{1}$ and Byung Yoon Choi $^{2}$ \\ ${ }^{1}$ Department of Otorhinolaryngology, Seoul National University Hospital, Seoul National University College of Medicine, Seoul, \\ ${ }^{2}$ Department of Otorhinolaryngology, Seoul National University Bundang Hospital, Seongnam, Korea
}

\author{
Received August 21, 2014 \\ Revised August 25, 2014 \\ Accepted August 27, 2014
}

Hearing loss is one of the most common sensorineural disorder. More than half of congenital bilateral profound deafness cases have been estimated to be attributed to genetic cause. Identification of genetic cause can provide valuable information. We developed new diagnostic strategy combining phenotype-driven candidate gene approach and targeted exome sequencing to find out the causative mutation of hearing loss. The causative mutation detection rates of this strategy were $78.1 \%$ and $54.8 \%$ in Korean multiplex families and sporadic severe to profound hearing loss families, respectively. The most frequent causative genes of Korean multiplex families were SLC26A4 and POU3F4. The other causative genes were MRNR1, WFS1, COCH, TECTA, MYO6, COL11A2, EYA4, GJB3, OTOF, STRC, MYO3A, and GJB2. The most frequent causative gene of Korean sporadic severe to profound hearing loss families was SLC26A4 followed by GJB2, CHD7, and CDH23. Based upon the results, the value of this strategy as a diagnostic tool seems to be promising. Although whole genome and exome sequencing have advanced as the development of next-generation sequencing, this new strategy could be a good screening and diagnostic tool to find the causative mutations. Korean J Audiol 2014;18(2):45-49

KEY WORDS: Targeted resequencing · Hearing loss · Molecular genetic test.

\section{Introduction}

Hearing loss is one of the most common sensorineural disorder and affects one out of 500 live births. The prevalence of hearing loss increases as children get old. ${ }^{1)}$ While many causes such as viral infections, ototoxic drugs and acoustic trauma could induce hearing loss, more than half of congenital bilateral profound deafness cases has been estimated to be attributed to genetic cause. ${ }^{2,3)}$

As considerable portion of genetic hearing loss is monogenic, the deafness phenotype could be predicted relatively accurately from genetic diagnosis. Identification of genetic cause can provide valuable information without further expensive testing. ${ }^{4)}$ First, the prognosis of hearing, whether hearing loss will be worsen or not, could be predicted. Second, knowing the cause of hearing loss will allow prediction of the efficacy of

This is an Open Access article distributed under the terms of the Creative Commons Attribution Non-Commercial License (http://creativecommons. org/licenses/by-nc/3.0/) which permits unrestricted non-commercial use, distribution, and reproduction in any medium, provided the original work is properly cited. certain therapeutic approaches and optimal intervention could be performed. For example, in genetic hearing loss with mutations of specific genes, such as, GJB2, SLC26A4, COCH, OTOF, and $M Y H 9$, mitochondrial mutations, cochlear implantation is supposed to lead to successful results. ${ }^{5)}$ Third, the possibility that future children or other family members would have hearing loss could be estimated. ${ }^{5-7)}$ Fourth, identification of mutations of hearing loss genes could detect the specific cause of a children's hearing loss, which cannot be identified by Universal Newborn Hearing Screening. ${ }^{4)}$ From this, in children, to whom the linguistic development is crucial, early intervention could be performed. ${ }^{8)}$ Therefore, genetic testing has become an important component for diagnosis of congenital hearing loss from etiologic and prognostic perspectives. Recently, as next-generation sequencing has been used commonly, the genetic diagnosis could be performed with high-throughput sequence analysis. We developed new diagnostic pipeline with next-generation sequencing. This paper will describe the result of our new diagnostic pipeline combining phenotype-driven candidate gene approach and targeted exome sequencing (TES) to 
find out the causative mutation of hearing loss.

\section{Various Application of Next-Generation Sequencing (NGS) in Deafness}

Genetic etiology of sensorineural hearing loss (SNHL) is extraordinarily heterogeneous. Therefore, to identify causative mutation in each patient, all the candidate genes should be screened. Before the era of next-generation sequencing, screening all the candidate genes was impossible. The previous method detecting the disease causing mutation was sequencing specific candidate gene and it was limited to the genes related to a certain phenotypic marker, such as GJB2, SLC26A4, or OTOF. This method could find out the causative mutation in only $10-20 \%$ of familial nonsyndromic hearing loss (NSHL). It was impossible to idetify the causative mutation in NSHL cases which were not related to a certain phenotypic marker. Therefore there has been a need to develop a new method to find out causative mutation in the patient with hearing loss. This need could be satisfied with next-generation sequencing (NGS). Studies for finding the causative mutation in hearing loss patients have grown rapidly with the advancement of NGS technique. NGS allowed whole genome, whole exome, and targeted gene sequencing to be more feasible and it leaded to easier identification of the causative mutation. ${ }^{4)}$ However, whole genome sequencing is still too expensive and too much compared to other sequencing. While, whole exome sequencing includes just exome, which is protein coding regions (exons) and constitute $1 \%$ of the human genome. Eighty five percent of the mutations with large effects on disease-related traits habor at exome. TES includes a certain set of target genes. Therefore it is much cheaper and faster than Sanger sequencing of each gene or whole exome sequencing and has deeper coverage. Therefore a numerous deafness samples could be screened through TES without substantial cost of time and money. ${ }^{4)}$ TES has contributed to identification of novel genes causing hereditary hearing loss. ${ }^{9-13)}$ The efficacy of TES has been reported from several studies. ${ }^{14-16)}$

\section{Customized Hierarchical Molecular Genetic Test Protocol in Koreans}

Based upon TES, we developed new diagnostic strategy combining phenotype-driven candidate gene approach and TES to find out the causative mutation of hearing loss. First, patients with certain phenotypic marker related to the hearing loss genes underwent Sanger sequencing to identify variants in corresponding candidate genes. Then GJB2 sequencing was performed for the remaining patients because the mutation in GJB2 was one of the most frequent mutation in NSHL cases.
Next, we performed TES. The number of candidate genes of TES and filtering steps were different according to the cases. In multiplex families, which has two or more NSHL members, 80 reported NSHL-related genes were screened (TES80). After aligned to the human genome reference sequence (hg19), selected single nucleotide variations or indels were filtered through five steps which used the property of multiplex family. As a basic step, the variants with a low quality score $(<20)$ were excluded. Then the variants, which did not coincide with the inheritance pattern of mulplex family, were discarded. Remained variants were checked in 80 normal hearing population and detected variants were excluded. Finally, segregation study in other families was performed by Sanger sequencing. Phenotype matching was also considered.

In sporadic severe to profound hearing loss families, 204 reported hearing loss-related genes were screened (TES-204). The results were aligned to the human genome reference sequence (hg19). Variants, which were detected in our in-house database composed of exomes of 81 Korean individuals, were excluded. Then low quality of genotyping $(<30)$ and reads $(<20)$ were discarded. The inheritance pattern of hearing loss was also checked. Lastly, the variants identified in our 276 Korean normal hearing control chromosomes were excluded.

\section{Genetic Etiology in Korean Multiplex Families}

Our new diagnostic strategy was performed in 32 multiplex families to find out the causative mutations. ${ }^{16)}$ Among 32 probands, 11 probands showed specific phenotype. Five probands showed bilateral enlarged vestibular aqueduct and another 5 probands showed incomplete partition type III on temporal bone CT. Each proband underwent Sanger sequencing of the corresponding candidate genes, SLC26A4 and POU3F4, respectively. In addition to 10 probands, one proband showed specific maternal inheritance pattern of hearing loss and mitochondrial DNA genes were sequenced. As a result, the causative mutations were found in these eleven families (Table 1). The remained 21 NSHL probands underwent GJB2 sequencing and 2 probands were identified to have known pathogenic

Table 1. Phenotype-driven candidate gene approach and its detection rate of a causative mutation in Korean multiplex families

\begin{tabular}{llc}
\hline Gene & \multicolumn{1}{c}{ Phenotype } & $\begin{array}{c}\text { Detection } \\
\text { rate }[\mathrm{n} / \mathrm{N}(\%)]\end{array}$ \\
\hline SLC26A4 & $\begin{array}{c}\text { Nonsyndromic enlarged vestibular } \\
\text { aqueduct }\end{array}$ & $5 / 5(100)$ \\
POU3F4 & Incomplete partition type III & $5 / 5(100)$ \\
MTRNR1 & Maternal transmission & $1 / 1(100)$ \\
\hline Total & & $11 / 11(100)$ \\
\hline
\end{tabular}


Table 2. Targeted exome sequencing of 80 deafness genes in Korean multiplex families

\begin{tabular}{|c|c|c|c|c|c|c|c|c|}
\hline Patient & Gene & Inheritance & Type & Chr & Genbank No. & Exon & Nucleotide & Protein \\
\hline SB14-30 & WFSI & $A D$ & Nonsynonymous & 4 & NM_006005 & Exon 8 & c.T1235C & p.V412A \\
\hline SB50-94 & $\mathrm{COCH}$ & $A D$ & Nonsynonymous & 14 & NM_001135058 & Exon 4 & C.T341C & P.L114P \\
\hline SB54-101 & OTOR & $A D$ & Stopgain & 20 & NM_020157 & Exon 2 & c.G223T & p.E75X \\
\hline SB60-107 & MYO6 & $A D$ & Stopgain & 6 & NM_004999 & Exon 8 & c.C613T & P.R205X \\
\hline SB61-109 & $C O L 11 A 2$ & $A D$ & Nonsynonymous & 6 & NM_080680 & Exon 30 & c.C2336T & P.P779L \\
\hline $\mathrm{SH} 14-37$ & $\mathrm{COCH}$ & $A D$ & Nonsynonymous & 14 & NM_001135058 & Exon 3 & C.G113A & p.G38D \\
\hline SH2O-47 & EYA4 & $A D$ & Nonsynonymous & 6 & NM_172103 & Exon 11 & c.C909G & p.F303L \\
\hline $\mathrm{SH} 21-50$ & MYO6 & $A D$ & Stopgain & 6 & NM_004999 & Exon 8 & c.C613T & P.R205X \\
\hline SH40-89 & GJB3 & $A D$ & Nonsynonymous & 1 & NM_001005752 & Exon 2 & c.G250A & p.V84I \\
\hline \multirow[t]{2}{*}{ SB04-11 } & \multirow[t]{2}{*}{ OTOF } & \multirow{2}{*}{$\begin{array}{r}\text { AR (compound } \\
\text { heterozygote) }\end{array}$} & Frameshift deletion & 2 & NM_194322 & Exon 24 & c.3133delC & P.R1045Gfs*28 \\
\hline & & & Stopgain & 2 & NM_194322 & Exon 8 & c.C1122G & p.Y374X \\
\hline SB38-75 & STRC & AR (homozygote) & Stopgain & 15 & NM_153700 & Exon 20 & c.C4057T & P.Q1353X \\
\hline \multirow[t]{2}{*}{ SB47-91 } & \multirow[t]{2}{*}{ MYO3A } & \multirow{2}{*}{$\begin{array}{r}\text { AR (compound } \\
\text { heterozygote) }\end{array}$} & Nonsynonymous & 10 & NM_017433 & Exon 7 & c.C580A & p.P194T \\
\hline & & & Frameshift insertion & 10 & NM_017433 & Exon 16 & c.1582_1583insT & p.Y530Lfs*9 \\
\hline \multirow[t]{2}{*}{ SH35-75 } & \multirow[t]{2}{*}{ GJB2 } & \multirow{2}{*}{$\begin{array}{r}\text { AR (compound } \\
\text { heterozygote) }\end{array}$} & Frameshift deletion & 13 & NM_004004 & Exon 2 & c.299_300del & p.H100Rfs*14 \\
\hline & & & Frameshift deletion & 13 & NM_004004 & Exon 2 & c. $235 \mathrm{delC}$ & p.L79Cfs*3 \\
\hline
\end{tabular}

Chr: chromosome, No.: number, AD: autosomal dominance, AR: autosomal recessive

mutations in GJB2 gene. Nest, TES of 80 reported NSHL-related genes (TES-80) was performed in 20 probands including one proband with mutations in GJB2 gene. Then five filtering steps, as mentioned above, were performed. Finally, among 20 probands, 13 probands found out their causative mutations (Table 2).

Consequently, among 32 multiplex families, the causative mutations were identified in 25 probands $(78.1 \%)$ by our new diagnostic strategy combining phenotype-driven candidate gene approach and TES. Analyzing the results of all cases, molecular genetic diagnosis was completed in $9(69.2 \%)$ form 13 autosomal dominant families and $9(75.0 \%)$ from 12 recessive families. The causative gene of autosomal dominant families included WFS1, COCH, TECTA, MYO6, COL11A2, EYA4, and $G J B 3$. The causative gene of autosomal recessive families included OTOF, STRC, MYO3A, GJB2, and SLC26A4. The causative mutations of remained families were one $M R N R 1 \mathrm{mu}-$ tation with maternal inheritance and 5 POU $3 F 4$ mutation with $\mathrm{X}$-linked inheritance.

\section{Genetic Etiology in Korean Sporadic Severe to Profound Hearing Loss Families}

Our new diagnostic strategy combining phenotype-driven candidate gene approach and TES was performed in 93 patients with severe to profound SNHL to find out the causative mutation of hearing loss. Among 93 probands, 42 probands showed certain phenotypic marker related to the hearing loss genes and were subject to Sanger sequencing of related can-
Table 3. Phenotype-driven candidate gene approach and its detection rate of a causative mutation in Korean sporadic severe to profound hearing loss families

\begin{tabular}{llc}
\hline \multicolumn{1}{c}{ Gene } & \multicolumn{1}{c}{ Phenotype } & $\begin{array}{c}\text { Detection } \\
\text { rate }[\mathrm{n} / \mathrm{N}(\%)]\end{array}$ \\
\hline SLC26A4 & $\begin{array}{c}\text { Nonsyndromic enlarged } \\
\text { vestibular aqueduct }\end{array}$ & $13 / 13(100)$ \\
CHD7 & $\begin{array}{c}\text { Charge syndrome } \\
\text { (mostly de novo) } \\
\text { Incomplete partition } \\
\text { POU3F4 III }\end{array}$ & $7 / 9(77.7)$ \\
TMPRSS3 & $\begin{array}{c}\text { Ski slope type high } \\
\text { frequency hearing loss }\end{array}$ & $3 / 7(100)$ \\
KCNQ1 \& KCNE1 & $\begin{array}{c}\text { Long QT syndrome } \\
\text { OTOF, Pejvakin }\end{array}$ & $\begin{array}{c}\text { Auditory neuropathy } \\
\text { spectrum disorder }\end{array}$ \\
FGF3 & $\begin{array}{c}\text { Complete labyrinthine } \\
\text { aplasia or cochlear } \\
\text { hypoplasia }\end{array}$ & $1 / 1(100)$ \\
\hline Total & & $0 / 2(0)$ \\
\hline
\end{tabular}

didate genes. Thirty (71.4\%) of 42 probands completed molecular genetic diagnosis successfully. Probands who showed enlarged vestibular aqueduct $(n=13)$, incomplete partition type III $(\mathrm{n}=5)$ and long $\mathrm{Q}-\mathrm{T}$ syndrome $(\mathrm{n}=1)$ were subject to direct sequencing of SLC26A4, POU3F4, and KCNQ1, respectively. The pathogenic variants were detected in all these probands. Other probands, who underwent direct sequencing of $\mathrm{CHD} 7$, TMPRSS3, and OTOF, showed the detection rate of $77.7 \%$, $42.3 \%$, and $20 \%$, respectively. Therefore, enlarged vestibular aqueduct, incomplete partition type III, and long Q-T syndrome were the phenotype markers which predicted pathogenic variants most accurately (Table 3). Fifty one probands without phe- 
Table 4. Targeted exome sequencing of 204 deafness genes in Korean sporadic severe to profound hearing loss families

\begin{tabular}{|c|c|c|c|c|c|c|c|c|}
\hline Patient & Gene & Inheritance & Type & $\mathrm{Chr}$ & Genbank No. & Exon & Nucleotide & Protein \\
\hline $\mathrm{SHJ} 4$ & $\mathrm{CDH} 23$ & AR (homozygote) & Nonsynonymous & 10 & NM_022124 & Exon 8 & c.C719T* & p.P240L* \\
\hline \multirow[t]{2}{*}{$\mathrm{SHJ} 23$} & \multirow[t]{2}{*}{ MYO7A } & \multirow{2}{*}{$\begin{array}{r}\text { AR (compound } \\
\text { heterozygote) }\end{array}$} & Stopgain & 11 & NM_000260 & Exon 3 & c.C52T & P.Q18X \\
\hline & & & Stopgain & 11 & NM_000260 & Exon 18 & c.C2115A & p.C705X \\
\hline \multirow[t]{2}{*}{ SHJ33 } & \multirow[t]{2}{*}{$\mathrm{CDH} 23$} & \multirow{2}{*}{$\begin{array}{c}\text { AR (compound } \\
\text { heterozygote) }\end{array}$} & Nonsynonymous & 10 & NM_022124 & Exon 8 & c.C719T* & p.P240L* \\
\hline & & & Nonsynonymous & 10 & NM_022124 & Exon 37 & c.C $4853 \mathrm{~A}$ & p.T1618K \\
\hline \multirow[t]{2}{*}{ SHJ4l } & \multirow[t]{2}{*}{$\mathrm{CDH} 23$} & \multirow{2}{*}{$\begin{array}{r}\text { AR (compound } \\
\text { heterozygote) }\end{array}$} & Nonsynonymous & 10 & NM_022124 & Exon 42 & c.G5747A & P.R1916H \\
\hline & & & Nonsynonymous & 10 & NM_022124 & Exon 46 & c.G6604A & p.D2202N \\
\hline \multirow[t]{2}{*}{ SHJ52 } & \multirow[t]{2}{*}{ PCDH15 } & \multirow{2}{*}{$\begin{array}{r}\text { AR (compound } \\
\text { heterozygote) }\end{array}$} & Nonsynonymous & 10 & NM_001142769 & Exon 36 & c. $5035 \mathrm{G}>\mathrm{C}$ & p.V1679L \\
\hline & & & Frameshift deletion & 10 & NM_001142763 & Exon 23 & c.2927delA & p.GIn976Argfs*18 \\
\hline \multirow[t]{2}{*}{ SHJ70 } & \multirow[t]{2}{*}{ MYO15A } & \multirow{2}{*}{$\begin{array}{c}\text { AR (compound } \\
\text { heterozygote) }\end{array}$} & Stopgain & 17 & NM_016239 & Exon 2 & c.G535T & p.El79X \\
\hline & & & Nonsynonymous & 17 & NM_016239 & Exon 10 & c.G4252A & p.G1418R \\
\hline \multirow[t]{2}{*}{ SNUBH71-123 } & \multirow[t]{2}{*}{ MYO15A } & \multirow{2}{*}{$\begin{array}{l}\text { AR (compound } \\
\text { heterozygote) }\end{array}$} & Splice donor variant & 17 & NM_016239 & Exon 10 & c. $4320+1 G>A$ & \\
\hline & & & Nonsynonymous & 17 & NM_016239 & Exon 46 & c.T8396A & p.L2799H \\
\hline \multirow[t]{2}{*}{ SNUH10-28 } & \multirow[t]{2}{*}{ MYO7A } & \multirow{2}{*}{$\begin{array}{r}\text { AR (compound } \\
\text { heterozygote) }\end{array}$} & Nonsynonymous & 11 & NM_000260 & Exon 23 & c.C2724G & p.D908E \\
\hline & & & Nonsynonymous & 11 & NM_000260 & Exon 29 & c.C3701G & p.T1234s \\
\hline \multirow[t]{2}{*}{ SHJ37 } & \multirow[t]{2}{*}{ USH2A } & \multirow{2}{*}{$\begin{array}{c}\text { AR (compound } \\
\text { heterozygote) }\end{array}$} & Nonsynonymous & 1 & NM_206933 & Exon 64 & c.T14017C & p.Y4673H \\
\hline & & & Nonsynonymous & 1 & NM_206933 & Exon 2 & c.C419A & p.Pl40H \\
\hline
\end{tabular}

Chr: chromosome, No.: number, AR: autosomal recessive

notypic marker underwent GJB2 sequencing and the pathogenic variants were detected in 10 probands. As a result, the pathogenic variants were identified in $40(43.0 \%)$ out of 93 probands through phenotype-driven candidate gene approach. Fifty three remained probands were subjected to TES-204. However, 8 probands rejected TES-204 and 45 probands underwent TES204. The causative mutations were detected in 11 (24.4\%) out of 45 probands. Nine out of 11 causative mutations were newly detected through TES-204 (Table 4). These causative mutations resided at $C D H 23(\mathrm{n}=3), M Y O 15 A(\mathrm{n}=2), M Y O 7 A(\mathrm{n}=2), A C T G 1$ $(\mathrm{n}=1), U S H 2 A(\mathrm{n}=1), P C D H 15(\mathrm{n}=1)$, and MYO3A $(\mathrm{n}=1)$.

Consequently, the causative mutations were identified in 51 (54.8\%) out of 93 sporadic severe to profound SNHL patients. At least $54.8 \%$ of sporadic severe to profound SNHL patients seemed to be monogenic Mendelian disorders in Koreans. The mutations in SLC26A4 and GJB2 were the most common causative mutations and responsible for $24.7 \%$ (23/93) of total patients.

\section{Conclusions}

In this paper, we demonstrated the value of new diagnostic strategy combining phenotype-driven candidate gene approach and TES for detecting causative mutations. The causative mutations in Korean familial NSHL and sporadic severe to profound SNHL patients were presented. Based upon the results, the value of this strategy as a diagnostic tool seems to be promising. Although whole genome and exome sequencing have advanced as the development of NGS, this new strategy could be a good screening and diagnostic tool to find the causative mutations.

\section{REFERENCES}

1) Hilgert N, Smith RJ, Van Camp G. Forty-six genes causing nonsyndromic hearing impairment: which ones should be analyzed in DNA diagnostics? Mutat Res 2009;681:189-96.

2) Scott DA, Carmi R, Elbedour K, Yosefsberg S, Stone EM, Sheffield VC. An autosomal recessive nonsyndromic-hearing-loss locus identified by DNA pooling using two inbred Bedouin kindreds. Am J Hum Genet 1996;59:385-91.

3) Yuan Y, You Y, Huang D, Cui J, Wang Y, Wang Q, et al. Comprehensive molecular etiology analysis of nonsyndromic hearing impairment from typical areas in China. J Transl Med 2009;7:79.

4) Lin X, Tang W, Ahmad S, Lu J, Colby CC, Zhu J, et al. Applications of targeted gene capture and next-generation sequencing technologies in studies of human deafness and other genetic disabilities. Hear Res 2012;288:67-76.

5) Wu CC, Lee YC, Chen PJ, Hsu CJ. Predominance of genetic diagnosis and imaging results as predictors in determining the speech perception performance outcome after cochlear implantation in children. Arch Pediatr Adolesc Med 2008;162:269-76.

6) Black J, Hickson L, Black B, Perry C. Prognostic indicators in paediatric cochlear implant surgery: a systematic literature review. Cochlear Implants Int 2011;12:67-93.

7) Kabatova Z, Profant M, Simkova L, Groma M, Nechojdomova D. Cochlear implantation in malformed inner ear. Bratisl Lek Listy 2009; 110:609-13.

8) Dror AA, Avraham KB. Hearing impairment: a panoply of genes and functions. Neuron 2010;68:293-308.

9) Pierce SB, Walsh T, Chisholm KM, Lee MK, Thornton AM, Fiumara A, et al. Mutations in the DBP-deficiency protein HSD17B4 cause ovarian dysgenesis, hearing loss, and ataxia of Perrault Syndrome. Am J Hum Genet 2010;87:282-8.

10) Rehman AU, Morell RJ, Belyantseva IA, Khan SY, Boger ET, Shahzad $\mathrm{M}$, et al. Targeted capture and next-generation sequencing identifies 
C9orf75, encoding taperin, as the mutated gene in nonsyndromic deafness DFNB79. Am J Hum Genet 2010;86:378-88.

11) Shearer AE, DeLuca AP, Hildebrand MS, Taylor KR, Gurrola J 2nd, Scherer S, et al. Comprehensive genetic testing for hereditary hearing loss using massively parallel sequencing. Proc Natl Acad Sci U S A 2010;107:21104-9.

12) Walsh T, Shahin H, Elkan-Miller T, Lee MK, Thornton AM, Roeb $\mathrm{W}$, et al. Whole exome sequencing and homozygosity mapping identify mutation in the cell polarity protein GPSM2 as the cause of nonsyndromic hearing loss DFNB82. Am J Hum Genet 2010;87:90-4.

13) Zheng J, Miller KK, Yang T, Hildebrand MS, Shearer AE, DeLuca AP, et al. Carcinoembryonic antigen-related cell adhesion molecule 16 interacts with alpha-tectorin and is mutated in autosomal domi- nant hearing loss (DFNA4). Proc Natl Acad Sci U S A 2011;108:421823.

14) Baek JI, Oh SK, Kim DB, Choi SY, Kim UK, Lee KY, et al. Targeted massive parallel sequencing: the effective detection of novel causative mutations associated with hearing loss in small families. Orphanet J Rare Dis 2012;7:60.

15) Brownstein Z, Friedman LM, Shahin H, Oron-Karni V, Kol N, Abu Rayyan A, et al. Targeted genomic capture and massively parallel sequencing to identify genes for hereditary hearing loss in Middle Eastern families. Genome Biol 2011;12:R89.

16) Choi BY, Park G, Gim J, Kim AR, Kim BJ, Kim HS, et al. Diagnostic application of targeted resequencing for familial nonsyndromic hearing loss. PLoS One 2013;8:e68692. 